\title{
A New Potentiometric Sensor for Determination of Pethidine Hydrochloride in Ampoules and Urine
}

\author{
Hazem M. Abu-Shawish ${ }^{1}$, Nasser Abu Ghalwa ${ }^{2}$, Ghada I. Khraish ${ }^{1}$, Jehad Hammad ${ }^{3}$ \\ ${ }^{1}$ Faculty of Science, Research Center, Al-Aqsa University, Gaza, Palestine \\ ${ }^{2}$ Chemistry Department, Al-Azhar University, Gaza, Palestine \\ ${ }^{3}$ Pharmacology Department, Faculty of Medicine, Islamic University, Gaza, Palestine \\ E-mail: hazemona1@yahoo.co.uk \\ Received August 28, 2010; revised November 10, 2010; accepted November 17, 2010
}

\begin{abstract}
A simple, precise, rapid and low-cost potentiometric method for pethidine determination in pharmaceuticals and urine is proposed. A chemically modified carbon paste electrode (CMCPE) for pethidine hydrochloride $(\mathrm{PDCl})$ based on pethidine-phosphotungstate (PD-PT) as ion-pair complex was prepared and fully characterized in terms of composition, usable $\mathrm{pH}$ range, response time and temperature. The pethidine electrode showed Nernstain responses in the concentration range $2.1 \times 10^{-6}-1.0 \times 10^{-2} \mathrm{M}$ with a detection limit of 7.3 $\times 10^{-7}$ and usable within the $\mathrm{pH}$ range $3.5-6.6$. This sensor exhibited a fast response time (about $5-8 \mathrm{~s}$ ), good stability. The value $(\mathrm{dE} / \mathrm{dt})$ of the electrode was found to be $0.00071 \mathrm{~V} /{ }^{\circ} \mathrm{C}$, which indicates fairly high thermal stability. Selectivity coefficients determined by matched potential method (MPM) and separate solution method (SSM) showed high selectivity for PDCl with respect to a large number of inorganic cations, organic cations, sugars and some common drug excipients. The sensor could be used successfully in the estimation of $\mathrm{PDCl}$ in ampoules and in spiked urine samples.
\end{abstract}

Keywords: Potentiometry, Carbon Paste Electrode, Pethidine, Ion-Selective Electrode

\section{Introduction}

Pethidine (Meperidine hydrochloride, Dolantin) (Ethyl, 1-methyl-4-phenylpiperidine-4-carboxylate hydrochloride), (Figure 1) is a potent opiate analgesics, which has been employed in the treatment of a variety of medical conditions [1]. Pethidine hydrochloride is also used as an illicit drug and therefore it is placed on the schedule II controlled substances list (drugs that have acceptable medical use and have high potential for abuse) in the United States and many other countries. Pethidine is also prescribed as a substitute for heroin [2], and often used medically as postoperative analgesia. In sports, athletes often take far higher doses of drugs than have been given for therapeutic use or in clinical studies to excel in competition. They have been barred to use by the International Olympic Committee and other sports organizations [3]. Therefore, determination of pethidine has important practical meanings. Many Several sophisticated analytical methods were reported to determine the pethidine such as high performance liquid chromatography (HPLC) $[4,5]$, gas chromatography [6], gas chromatography in combination with mass spectrometry (GC-MS) [7,8], spectrophotometry [9] and potentiometric analysis [10-14]. Many of these methods involve several time-consuming manipulations, extraction steps, derivatization reactions that are liable to various interferences, and are not applicable to colored and turbid solutions either.

Potentiometric methods with ion-selective electrodes (ISE's) have proved to be effective for the analysis of pharmaceutical formulations and biological samples, because these sensors offer the advantages of simple design, construction, and manipulation, reasonable selectivity, fast response time, applicability to colored and turbid solutions and possible interfacing with automated and computerized systems. [15-17]. A number of ISEs based on PVC membrane [10-14], for determination of pethidine have been reported. However, these electrodes still have certain inherent limitations. Cleary, there is an urgent need for a recipe that would make the fabrication and optimization of potentiometric sensors with low detection limit, high stability and reproducibility a straightforward process.

The advantages of carbon paste electrodes, such as che- 


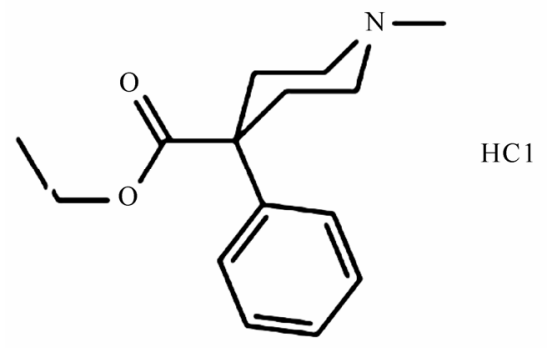

Figure 1. Chemical structure of pethidine hydrochloride.

mical inertness, robustness, low cost, renewability, very low background current, stable response, low ohmic resistance and no need for internal solution over conventional polymeric membrane electrodes has attracted the attention of researchers in recent years [15-18]. After careful review of literature, there is no report on determination of pethidine hydrochloride using a carbon paste electrode.

This paper describes the construction, potentiometric characterization, and analytical application of a pethidinechemically modified carbon paste electrode (D-CMCPE) based on the use of pethidine-phosphotungstate (PD-PT) as electroactive materials and 2-nitrophenyl octyl ether (2-NPOE) as plasticizer. The results presented in this paper show that the sensor constructed for pethidine ion has a wide concentration range, low limit of detection, good Nernstain slope, and high selectivity over a wide variety of other cations and compared with electrodes previously reported [10-14].

\section{Experimental}

\subsection{Reagents and Solutions}

Pethidine hydrochloride $\mathrm{PDCl}$ was obtained from general administration of pharmacy, ministry of health (GazaPalestine). Graphite powder, 2-nitrophenyl octyl ether (2-NPOE), dioctyl phthalate (DOP), dibutyl phthalate (DBP), tris(2-ethylhexyl) phosphate (DOPh), dioctyl sebacate (DOS), tributyl phosphate (TPh), tricresyl phosphate (TCP) and dibutyl butyl phosphonate (DDBP), as well as metal salts were purchased from Aldrich and used as received. Silicotungstic acid (STA), phosphotungstic acid (PTA), phosphomolybdic acid (PMA), silicomolybdic acid (SMA) and sodium tetraphenyl borate (Na-TPB) were obtained from Sigma.

\subsection{Apparatus}

Potentiometric measurements were carried out with a digital millivoltmeter (SR-MUL-3800). $\mathrm{pH}$ measurements were made on a digital $\mathrm{pH}$ meter (Wissenscha-ftlich-Te- chnische WerkstattenGmbH (WTW)-Germany) at room temperature $\left(25.0^{\circ} \mathrm{C} \pm 1.0^{\circ} \mathrm{C}\right)$.

\subsection{Preparation of Ion-Exchanger Complex}

An ion-exchanger complex was made from pethidine hydrochloride (PD) and one of the following substances: silicotungstic acid (STA), silicomolybdic acid (SMA) phosphotungstic acid (PTA), phosphomolybdic acid (PMA), or sodium tetraphenyl borate (Na-TPB) according to a previously reported method [19]. This precipitated ion-pair was washed, dried and used as the active substances for preparing the chemically modified carbon paste electrodes of pethidine hydrochloride.

\subsection{Preparation of the Electrode}

A Teflon holder (12 cm length) with a hole at one end (7 $\mathrm{mm}$ diameter, $3.5 \mathrm{~mm}$ deep) for the carbon paste filling served as the electrode body. Electrical contact was made with a stainless steel rod through the centre of the holder. This rod moved up and down by screw movement to press the paste down when renewal of the electrode surface was needed. Modified carbon paste was prepared by mixing weighed amounts of PD-PT and high purity graphite. The mixture was homogenized, and then the impregnated carbon powder was added to a weighed amount of 2-nitrophenyl octyl ether (2-NPOE). A very high degree of homogenization is then achieved by careful mixing with a glass rod in an agate mortar and subsequent thorough crushing with a pestle. The ready-prepared paste was then packed into the hole of the electrode body. The carbon paste was smoothed onto paper until it had a shiny appearance and was used directly for potentiometric measurements without preconditioning requirements.

\subsection{Sample Analysis}

The standard addition method in which small increments $(10-100 \mu \mathrm{l})$ of $(0.1 \mathrm{M}) \mathrm{TDCl}$ solution were added to 50 $\mathrm{mL}$ aliquot-samples of various concentrations $\left(5.0 \times 10^{-6}\right.$ to $\left.1.0 \times 10^{-5} \mathrm{M}\right) \mathrm{PDCl}$ was applied. The potential after each increment was recorded at $25^{\circ} \mathrm{C} \pm 0.1^{\circ} \mathrm{C}$ and used to calculate the concentration of $\mathrm{TDCl}$ in the drug samples.

The potentiometric titration of different volumes of $1.0 \times 10^{-3} \mathrm{M}$ and $1.0 \times 10^{-2} \mathrm{M}$ PDCl solution: $5-10 \mathrm{~mL}$ equivalent to $1.42-28.4 \mathrm{mg}$, were transferred to a $25 \mathrm{~mL}$ beaker, and titrated with a standard solutions of Na-TPB and PTA using the prepared PD-electrode as indicator electrode. The end points were determined from the S-shaped curve.

In the calibration graph method, different amounts of 
$\mathrm{PDCl}$ were added to $50 \mathrm{~mL}$ of water comprising a concentration range from $1.0 \times 10^{-7}$ to $1.0 \times 10^{-2} \mathrm{M}$ and the measured potential was recorded using the present electrode. Data were plotted as potential versus logarithm of the $\mathrm{PD}^{+}$activity and the resulting graph was used for subsequent determination of unknown drug concentration [20].

\subsection{Analysis of Spiked Urine Samples}

The samples ( $5 \mathrm{ml}$ of urine) were spiked with pethidine hydrochloride and left stirred for $5 \mathrm{~min}$, transferred to a $25 \mathrm{~mL}$ volumetric flask and completed to the mark with distilled water to give $5.0 \times 10^{-6}$ to $1.0 \times 10^{-5} \mathrm{M} \mathrm{PDCl}$. These solutions were subjected to the standard additions method or the calibration graph method for $\mathrm{PDCl}$ determination [21].

\section{Result and Discussion}

\subsection{Characteristics of the Electrode}

The general characteristics of sensor are outlined by determining its sensitivity, detection limit, linear range and selectivity coefficients. Some important features of carbon paste electrode, such as the properties of the plasticizer, the graphite $(\mathrm{G})$ /plasticizer $(\mathrm{P})$ ratio, the nature and amount of the ion-exchanger complex, are reported to significantly influence the sensitivity and selectivity of the sensor.

\subsubsection{Effect of Ion-Exchanger}

Ion-exchanger complex used in ISEs should have rapid exchange kinetics and adequate formation constants in the paste. In addition, they should have good solubility in the paste matrix and sufficient lipophilicity to prevent leaching from the paste into the sample solution $[22,23]$. The ion-exchangers of PD-ST, PD-SM, PD-PT, PD-PM and PD-TPB were prepared and tested as modifiers for the present electrode. The influences of the amount of the different pethidine ion-exchangers in the carbon paste were investigated and the corresponding results are summarized in Table 1. As can be seen, the electrode containing zero percentage of ion-exchanger complexes (sensor No. 1) showed a negligible response towards pethidine cations, whereas in the presence of the Ion-exchanger complexes the sensor displayed remarkable selectivity for pethidine cations, as found for electrode (composition \#2) that contains PD-PT and produced the widest concentration range, the lowest detection limit and shortest response time with Nernstain slope towards $\mathrm{PD}^{+}$cations. The other ion-exchangers gave inferior response. Further increase in the ratio of the ion-exchanger complexes (sensors No. 3 and 4), however, resulted in a little decrease in the response of the electrode, most probably due to some inhomogenieties and possible saturation of the paste [24].

\subsubsection{Effect of Graphite/Plasticizer (G/P) Ratio}

Different graphite/plasticizer ratios that is $0.85,0.95$, $1.05,1.15$ and 1.30 using 2-NPOE as plasticizer while keeping the amount of ion-exchanger complex constant (i.e. $0.5 \%$ ) were examined while optimizing the membrane composition as shown in Table 1. The paste with $(\mathrm{G} / \mathrm{P})$ ratio of 0.95 showed the optimum physical properties and ensured high enough mobilities of their constituents [25] and was found to give the best reproducibility and sensitivity of $54.2 \mathrm{mV}$ per decade over the widest linear concentration range of $2.1 \times 10^{-6}-1.0 \times$ $10^{-2} \mathrm{M}$ in comparison to the other ratios tested. Pastes with G/P more than 1.30 produced "crumbly" pastes and those with ratio smaller than 0.85 had a consistency resembling that of "peanut butter", i.e., not workable.

\subsubsection{Effect of Plasticizers}

Two parameters are of importance when manufacturing a carbon paste: 1) its mechanical stability and 2) its active surface area. Mechanical stability can be interpreted as the ability of the carbon paste to avoid erosion in solution. The use of plasticizers will give some permeable properties to the paste and will improve its mechanical stability by promoting binding between grains [26]. In addition, the solvent mediator, in particular, has a dual function: it acts as a liquifying agent, enabling homogenous solubilization and modifying the distribution constant of the ion-exchanger complex used. The proportion of solvent mediator must be optimized in order to minimize the electrical asymmetry of the paste, to keep the sensor as clean as possible, and to stop leaching to the aqueous phase [27]. In exploration for a suitable plasticizer for constructing this electrode, we used seven plasticizers, with the values of dielectric constants, lipophilicity and molecular weight respectively listed in parantheses, namely, 2-NPOE $\left(\varepsilon r=23.6, \mathrm{P}_{T L C}=5.9\right.$, M.wt. = 251), DOP $\left(\varepsilon r=5.1, \mathrm{P}_{T L C}=7.0\right.$, M.wt. $\left.=391\right)$, $\operatorname{DBP}\left(\varepsilon r=6.4, \mathrm{P}_{T L C}=4.5\right.$, M.wt. $\left.=278\right)$, DOS $(\varepsilon r=3.9$, $\mathrm{P}_{T L C}=10.1$, M.wt. $\left.=427\right), \mathrm{DOPh}\left(\varepsilon \mathrm{r}=4.8, \mathrm{P}_{T L C}=10.2\right.$, M.wt. = 434), TBP $\left(\varepsilon r=8.0, \mathrm{P}_{T L C}=4.0\right.$, M.wt. $\left.=266\right)$, $\mathrm{TCP}(\varepsilon \mathrm{r}=6.9$, M.wt. $=368)$ and DBBP $(\varepsilon r=4.6, \mathrm{M} . w t=$ $250)$ in sample electrodes to figure out the plasticizer with the best response. The sensor with 2-NPOE as a solvent mediator produced the best response, as shown in Figure 2, likely due to better dielectric characteristics of 2-NPOE comparing to other solvents, and the ability of 2-NPOE to extract pethidine ions from the aqueous solution to the organic paste phase [28]. 
Table 1. Optimization of paste ingredients of the pethidine sensor.

\begin{tabular}{|c|c|c|c|c|c|c|c|}
\hline \multicolumn{4}{|c|}{ Composition (\%) } & \multicolumn{4}{|c|}{ Electrode response } \\
\hline Sensor & I-E & $\mathrm{G}$ & P (2-NPOE) & $\mathrm{S}$ & C.R. & LOD & $\mathrm{R}_{(\mathrm{s})}$ \\
\hline \multicolumn{8}{|l|}{ PD-PT } \\
\hline $1-$ & -- & 51.5 & 48.5 & 40.8 & $1.7 \times 10^{-4}-1.0 \times 10^{-2}$ & $8.3 \times 10^{-5}$ & $20-25$ \\
\hline $2-$ & 0.5 & 48.5 & 51.0 & 54.2 & $2.1 \times 10^{-6}-1.0 \times 10^{-2}$ & $7.3 \times 10^{-7}$ & $5-8$ \\
\hline $3-$ & 1.0 & 48.2 & 50.8 & 50.9 & $5.3 \times 10^{-6}-1.0 \times 10^{-2}$ & $3.0 \times 10^{-6}$ & $8-12$ \\
\hline $4-$ & 2.0 & 47.8 & 50.2 & 48.2 & $5.7 \times 10^{-6}-1.0 \times 10^{-2}$ & $4.2 \times 10^{-6}$ & $10-12$ \\
\hline \multicolumn{8}{|l|}{ PD-PM } \\
\hline $5-$ & 0.5 & 48.5 & 51.0 & 48.3 & $6.6 \times 10^{-5}-1.0 \times 10^{-2}$ & $2.3 \times 10^{-5}$ & $13-15$ \\
\hline $6-$ & 1.0 & 48.2 & 50.8 & 48.5 & $7.9 \times 10^{-5}-1.0 \times 10^{-2}$ & $3.9 \times 10^{-5}$ & $20-23$ \\
\hline $7-$ & 2.0 & 47.8 & 50.2 & 47.1 & $9.2 \times 10^{-5}-1.0 \times 10^{-2}$ & $5.3 \times 10^{-5}$ & $17-20$ \\
\hline \multicolumn{8}{|l|}{ PD-ST } \\
\hline $8-$ & 0.5 & 48.5 & 51.0 & 47.1 & $5.2 \times 10^{-6}-1.0 \times 10^{-2}$ & $3.3 \times 10^{-6}$ & $10-13$ \\
\hline $9-$ & 1.0 & 48.2 & 50.8 & 46.5 & $8.5 \times 10^{-6}-1.0 \times 10^{-2}$ & $5.1 \times 10^{-6}$ & $12-15$ \\
\hline $10-$ & 2.0 & 47.8 & 50.2 & 46.2 & $9.4 \times 10^{-5}-1.0 \times 10^{-2}$ & $5.5 \times 10^{-6}$ & $15-18$ \\
\hline \multicolumn{8}{|l|}{ PD-SM } \\
\hline $11-$ & 0.5 & 48.5 & 51.0 & 51.5 & $3.6 \times 10^{-5}-1.0 \times 10^{-2}$ & $2.3 \times 10^{-5}$ & $12-15$ \\
\hline $12-$ & 1.0 & 48.2 & 50.8 & 49.6 & $5.9 \times 10^{-5}-1.0 \times 10^{-2}$ & $3.7 \times 10^{-5}$ & $15-20$ \\
\hline $13-$ & 2.0 & 47.8 & 50.2 & 49.0 & $7.8 \times 10^{-5}-1.0 \times 10^{-2}$ & $4.3 \times 10^{-5}$ & $20-23$ \\
\hline \multicolumn{8}{|l|}{ PD-TPB } \\
\hline $14-$ & 0.5 & 48.5 & 51.0 & 49.2 & $2.6 \times 10^{-5}-1.0 \times 10^{-2}$ & $1.3 \times 10^{-5}$ & $15-20$ \\
\hline $15-$ & 1.0 & 48.2 & 50.8 & 47.1 & $3.2 \times 10^{-5}-1.0 \times 10^{-2}$ & $1.7 \times 10^{-5}$ & $12-15$ \\
\hline $16-$ & 2.0 & 47.8 & 50.2 & 47.7 & $3.8 \times 10^{-5}-1.0 \times 10^{-2}$ & $2.0 \times 10^{-5}$ & $15-18$ \\
\hline \multicolumn{8}{|c|}{ PD-PT with different plasticizers } \\
\hline \multicolumn{8}{|l|}{ plasticizers } \\
\hline (2-NPOE) & 0.5 & 48.5 & 51.0 & 54.2 & $2.1 \times 10^{-6}-1.0 \times 10^{-2}$ & $7.3 \times 10^{-7}$ & $5-8$ \\
\hline (DOP) & 0.5 & 48.5 & 51.0 & 46.5 & $8.1 \times 10^{-5}-1.0 \times 10^{-2}$ & $5.5 \times 10^{-6}$ & $12-15$ \\
\hline (DBP) & 0.5 & 48.5 & 51.0 & 50.6 & $3.2 \times 10^{-5}-1.0 \times 10^{-2}$ & $1.0 \times 10^{-5}$ & $15-18$ \\
\hline (DOS) & 0.5 & 48.5 & 51.0 & 42.6 & $5.5 \times 10^{-5}-1.0 \times 10^{-2}$ & $3.2 \times 10^{-5}$ & $13-17$ \\
\hline$(\mathrm{DOPh})$ & 0.5 & 48.5 & 51.0 & 51.2 & $8.3 \times 10^{-6}-1.0 \times 10^{-2}$ & $6.5 \times 10^{-6}$ & $15-20$ \\
\hline (TCP) & 0.5 & 48.5 & 51.0 & 52.6 & $5.3 \times 10^{-6}-1.0 \times 10^{-2}$ & $2.5 \times 10^{-6}$ & $10-12$ \\
\hline (TBP) & 0.5 & 48.5 & 51.0 & 41.3 & $2.1 \times 10^{-4}-1.0 \times 10^{-2}$ & $1.7 \times 10^{-4}$ & $20-23$ \\
\hline (DBBP) & 0.5 & 48.5 & 51.0 & 40.9 & $1.8 \times 10^{-4}-1.0 \times 10^{-2}$ & $1.0 \times 10^{-4}$ & $20-25$ \\
\hline \multicolumn{8}{|c|}{ PD-PT with different $g / p$ ratios } \\
\hline \multicolumn{8}{|l|}{$\mathrm{g} / \mathrm{p}$ ratios } \\
\hline 0.85 & 0.5 & 45.7 & $53.8(2-\mathrm{NPOE})$ & 52.8 & $2.5 \times 10^{-6}-1.0 \times 10^{-2}$ & $8.7 \times 10^{-7}$ & $8-10$ \\
\hline 0.95 & 0.5 & 48.5 & $51.0(2-\mathrm{NPOE})$ & 54.2 & $2.1 \times 10^{-6}-1.0 \times 10^{-2}$ & $7.3 \times 10^{-7}$ & $5-8$ \\
\hline 1.05 & 0.5 & 51.0 & 48.5(2-NPOE) & 53.8 & $2.7 \times 10^{-6}-1.0 \times 10^{-2}$ & $8.1 \times 10^{-7}$ & $10-12$ \\
\hline 1.15 & 0.5 & 53.2 & 46.3 (2-NPOE) & 51.8 & $3.2 \times 10^{-6}-1.0 \times 10^{-2}$ & $1.3 \times 10^{-6}$ & $10-12$ \\
\hline 1.30 & 0.5 & 56.2 & 43.3 (2-NPOE) & 48.9 & $7.3 \times 10^{-6}-1.0 \times 10^{-2}$ & $4.4 \times 10^{-6}$ & $12-15$ \\
\hline
\end{tabular}

I. E: ion-exchanger complex, G: graphite, P: plasticizers, S: slope (mV/decade), C.R.: concentration range (M), LOD: limit of detection, R (s): response time (s). 


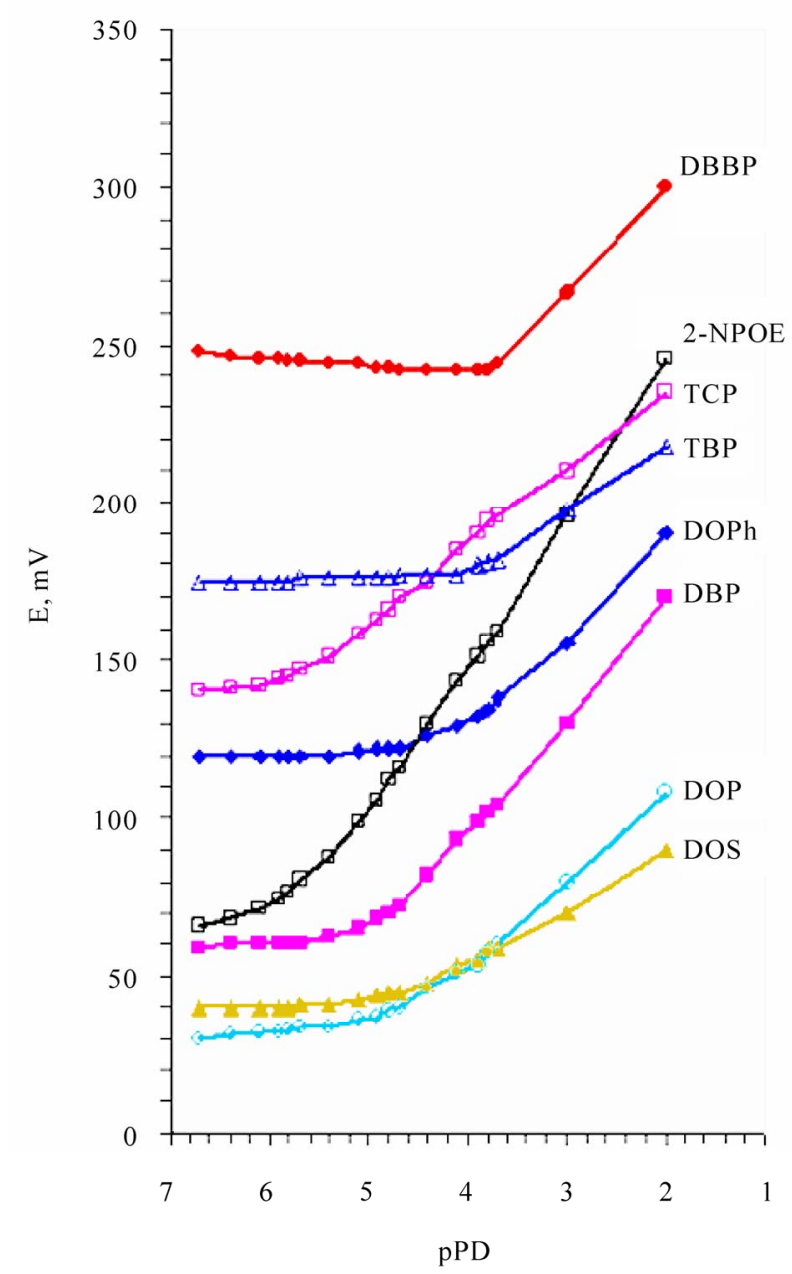

Figure 2. Effect of different plasticizers on the response of PD-CMCPE.

Among the different compositions studied, a paste containing ion-exchanger complex $0.5 \mathrm{wt} \% \mathrm{PD}-\mathrm{PT}, 48.5$ $\mathrm{wt} \%$ graphite, $51.0 \mathrm{wt} \%$ 2-NPOE exhibited the best response characteristics and the lowest detection limit. Therefore, this composition was used to study various operation parameters of the electrodes. The electrochemical performance characteristics of this electrode were systematically evaluated according to the IUPAC recommendations [29].

\subsection{Surface-Renewal and Reproducibility of the Electrode}

The main attraction of using the modified electrode is that the electrode surface can be renewed after every use. The bulk modified electrode can be renewed by squeezing a little carbon paste out of the tube and a fresh surface is smoothed on a piece of weighing paper whenever needed [30]. Accordingly, a paste of optimum composi- tion and suitable weight ( $1.5 \mathrm{~g})$ can be used for several months without any deterioration or change in the response of the electrode. The slope of the calibration graph was found to decrease slightly from 54.4 to 50.8 $\mathrm{mV} /$ decade after three times of use. This decrease may be attributed to memory effect due to the surface contamination [31]. In this case, the electrode surface should be renewed. The repeatability of the potential reading of the electrode was examined by subsequent measurements of $1 \times 10^{-4} \mathrm{M} \mathrm{PDCl}$ solution immediately after measuring the first set of solutions at $1.0 \times 10^{-3} \mathrm{M} \mathrm{PDCl}$. The standard deviation of measuring emf for 5 replicate measurements was found to be 1.127 for $1.0 \times 10^{-4} \mathrm{M}$ solution and 0.747 for $1.0 \times 10^{-3} \mathrm{M}$ solution.

\subsection{Response Time and Reversibility of the Electrode}

For analytical applications, dynamic response time is a significant parameter for any sensor. The response time of the electrode is defined as the time between addition of the analyte to the sample solution and the time when a limiting potential has been reached [29].

In this work, the response time of the electrode was measured by varying the pethidine concentration over the range $1.0 \times 10^{-5}$ to $1.0 \times 10^{-2} \mathrm{M}$. The electrode reaches equilibrium in about $5-8 \mathrm{~s}$. As shown in Figure 3. To evaluate the reversibility of the electrode, the potential measurements were performed in the sequence high-tolow (from $1.0 \times 10^{-2}$ to $1.0 \times 10^{-5} \mathrm{M}$ ) sample concentrations. Figure 3 showed that the response of the electrode was reversible; although the time needed to reach equilibrium values (12 s) was longer than that for low-to-high sample concentrations.

\subsection{Effect of Diverse Ions}

The separate solution method (SSM) is recommended by IUPAC to determine the selectivity coefficient of the ISE [32]. SSM is based on Nickolsky-Eisenman equation. However, it has been shown that this method suffers some limitations in terms of the values for ions of unequal charges, a non-Nernstain behavior of interfering ions [33]. Therefore another method named the "matched potential method (MPM)" was recommended [32] especially when the primary ion and/or the interfering ion dissatisfy with the Nernst response or when the involved ions have unequal charges [34]. The resulting values, presented in Table 2, show that the electrode display significantly high selectivity for pethidine over many common organic and inorganic compounds, drugs, sugars, amino acids as well as some anions. In pharmaceutical analysis, it is important to test the selectivity towards 


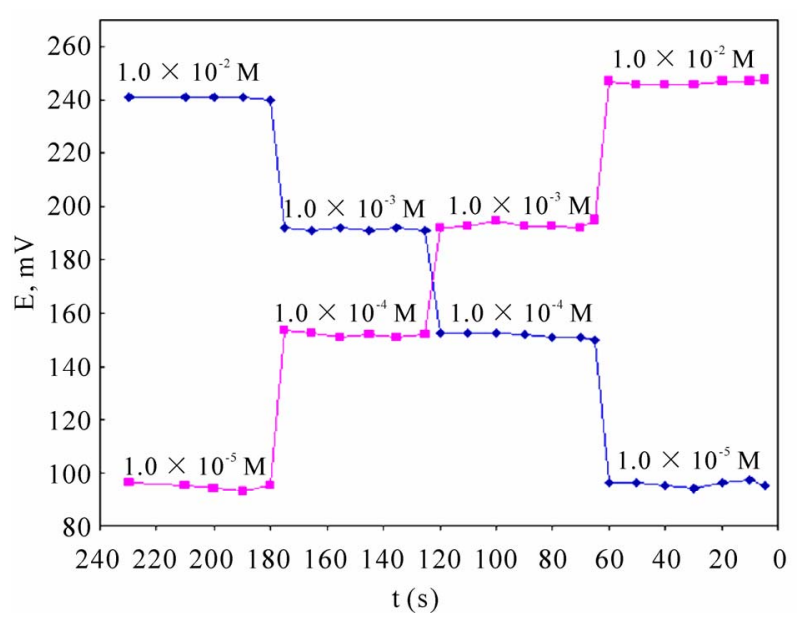

Figure 3. Dynamic response of sensor A for step changes in concentration of pethidine hydrochloride (from low to high and vice versa).

Table 2. Selectivity coefficients of various interfering ions for PD-CMCPE.

\begin{tabular}{|c|c|c|}
\hline Interfering ions & SSM & MPM \\
\hline $\mathrm{NH}^{+}$ & $1.41 \times 10^{-4}$ & $8.41 \times 10^{-5}$ \\
\hline $\mathrm{Na}^{+}$ & $9.52 \times 10^{-5}$ & $1.18 \times 10^{-5}$ \\
\hline $\mathrm{K}^{+}$ & $2.71 \times 10^{-4}$ & $1.20 \times 10^{-4}$ \\
\hline $\mathrm{Li}^{+}$ & $4.34 \times 10^{-4}$ & $1.66 \times 10^{-4}$ \\
\hline $\mathrm{Cd}^{2+}$ & $5.69 \times 10^{-4}$ & $8.34 \times 10^{-6}$ \\
\hline $\mathrm{Mg}^{2+}$ & $1.94 \times 10^{-4}$ & $7.81 \times 10^{-6}$ \\
\hline $\mathrm{Ca}^{2+}$ & $1.13 \times 10^{-4}$ & $2.10 \times 10^{-5}$ \\
\hline $\mathrm{Ba}^{2+}$ & $8.02 \times 10^{-4}$ & $2.02 \times 10^{-5}$ \\
\hline $\mathrm{Zn}^{2+}$ & $2.73 \times 10^{-4}$ & $5.11 \times 10^{-5}$ \\
\hline $\mathrm{Co}^{2+}$ & $1.19 \times 10^{-4}$ & $3.85 \times 10^{-5}$ \\
\hline $\mathrm{Al}^{3+}$ & $6.98 \times 10^{-4}$ & $7.73 \times 10^{-5}$ \\
\hline $\mathrm{Ce}^{3+}$ & $1.86 \times 10^{-4}$ & $4.30 \times 10^{-5}$ \\
\hline Diclofenac sodium & $2.53 \times 10^{-2}$ & $4.86 \times 10^{-2}$ \\
\hline Spiramycine & $3.41 \times 10^{-2}$ & $4.86 \times 10^{-2}$ \\
\hline $\begin{array}{c}\text { Spectinomycine } \\
\mathrm{Hcl}\end{array}$ & $2.93 \times 10^{-2}$ & $2.47 \times 10^{-2}$ \\
\hline Captopril & $6.76 \times 10^{-2}$ & $2.45 \times 10^{-2}$ \\
\hline Ephidrine & $1.27 \times 10^{-2}$ & $8.89 \times 10^{-3}$ \\
\hline Lidocaine & $1.27 \times 10^{-1}$ & $4.86 \times 10^{-2}$ \\
\hline D-Fractose & - & $9.14 \times 10^{-7}$ \\
\hline D- Galactose & - & $1.35 \times 10^{-6}$ \\
\hline Maltose & - & $5.54 \times 10^{-6}$ \\
\hline Sucrose & - & $8.04 \times 10^{-6}$ \\
\hline Glucose & - & $2.47 \times 10^{-6}$ \\
\hline
\end{tabular}

the excipients such as such as lactose, glucose, sucrose, starch, stearic acid, magnesium stearate and microcrystalline cellulose and the fillers added to the pharmaceutical preparations. The interference of some of these excipients was explored and measured. It is found that they cause minor effect on the function of the electrode as shown in Table 2.

\subsection{Effect of Temperature}

To study the thermal stability of the sensor, calibration graphs were constructed at different test solution temperatures $20,30,40,50$ and $60^{\circ} \mathrm{C}$. From these graphs the electrode potentials at $\mathrm{pPD}=0$ were obtained and plotted versus $(t-25)$, where $t$ is the temperature of the experiment. A straight line plot was obtained for each electrode with slope represents the thermal coefficient value $(\mathrm{dE} / \mathrm{dt})$ of the electrode [35]. The value $(\mathrm{dE} / \mathrm{dt})$ of the electrode was found to be $0.00071 \mathrm{~V} /{ }^{\circ} \mathrm{C}$. This indicates fairly high thermal stability of the electrode within the investigated temperature range and shows no deviation from the theoretical Nernstian behavior.

\subsection{Effect of pH}

The $\mathrm{pH}$ dependence of the potentials of the proposed electrode was tested over the $\mathrm{pH}$ range $2.2-10.0$ for 1.0 $\times 10^{-5}$ and $1.0 \times 10^{-4} \mathrm{M} \mathrm{PDCl}$ solutions. The acidity was adjusted by adding small volumes of $(1.0 \mathrm{M} \mathrm{HCl}$ or $\mathrm{NaOH})$ to the test solutions and the variation in potential was followed. As it can be seen in Figure 4, the potential response remains almost constant over the $\mathrm{pH}$ range 2.7 6.8 which can be taken as the working $\mathrm{pH}$ range of the electrode. However, there is a slight deviation at $\mathrm{pH}$ values lower than 2.7 which may be due to $\mathrm{H}^{+}$interference. On the other hand, the potential decreases gradually at $\mathrm{pH}$ values higher than 6.8. This drop may be attributed to formation of free pethidine base in the test solution.

\section{Applications}

\subsection{Titration of Pethidine Solution with a Standard PTA and Na-TPB Solution}

The PD-CMCPE was successfully used as an indicator electrode in the potentiometric titration of $5 \mathrm{ml}$ of $0.01 \mathrm{M}$ (14.2 $\mathrm{mg}$ ) of pethidine hydrochloride with a standard solution of Na-TPB and PTA solution. The method for pethidine ion (PD) titration is based on the decrease of (PD) concentration by precipitation with PTA and Na-TPB standard solution. As is obvious from Figure 5, 


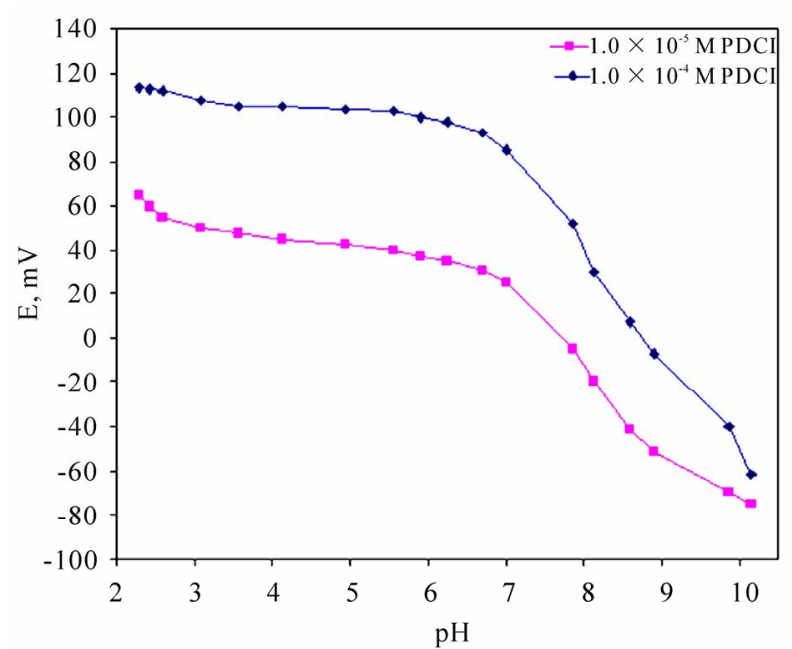

Figure 4. Effect of $\mathrm{pH}$ of the test solution on the potential response of $\mathrm{PD}-\mathrm{CMCPE}$.

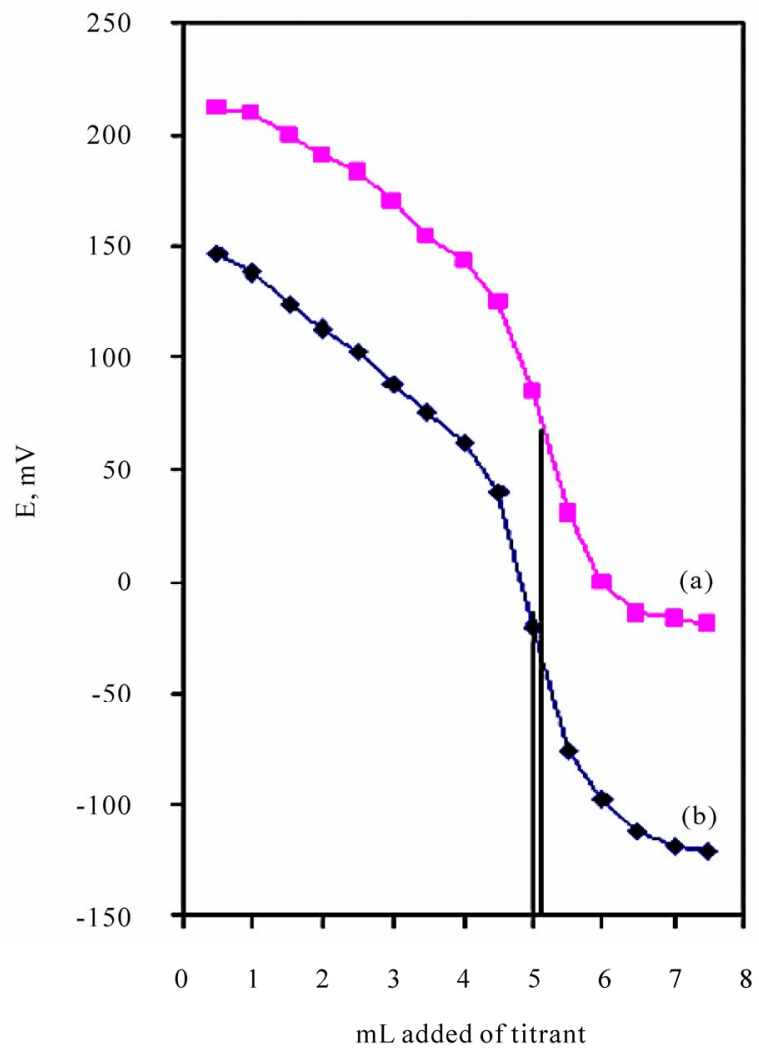

Figure 5. Potentiometric titration of $14.2 \mathrm{mg} \mathrm{PDCl}$ with Na-TPB (a) and PTA (b) as titrants using PD-CMCPE.

the amount of pethidine can be accurately determined from the end point of the titration curve.

\subsection{Determination of Pethidine in Ampoules}

The standard additions and calibration methods were applied for determination $\mathrm{PDCl}$ content in ampoule samples as can be seen in Table 3, the recovery of PDCl is almost quantitative.

\subsection{Recovery and Determination of Pethidine Ions in Urine}

Recovery experiments were conducted by spiking urine samples with appropriate amounts of pethidine ions, and determined by this electrode using the standard addition method and calibration curve. The results shown in Table 3. Recoveries and R.S.D. values range between $96.6 \%$ and $103.0 \%$ of pethidine, and 0.27 to 1.33 , respectively. It is noted that accurate and reproducible results Thus the sensor can be employed for quantification of pethidine in urine samples.

\section{Comparison of the Pethidine Selective Electrodes}

The performance characteristics of the proposed electrode and those of some reported carbon paste electrodes are presented in Table $\mathbf{4}$ for comparison. It is clear that the proposed electrode is comparable with most of the reported electrodes with regard to working concentration range, response time and low detection limit. Overall evaluation indicates this electrode is more useful in such applications.

\section{Conclusions}

The proposed chemically modified carbon paste electrode based on pethidine phosphotungstate as an electroactive ion exchanger complex might be a useful analytical tool and interesting alternative for the determination of PD ions in pharmaceutical preparations and urine samples. The electrode shows high sensitivity, reasonable selectivity, fast static response, long term stability and applicability over a wide concentration range with minimal sample pretreatment. The electrode developed is superior as compared with the pethidine selective electrode described in the literature [10-14].

\section{Acknowledgements}

The authors would like to thank Dr Muneer A. Alboursh and Dr Amal Zendah (general administration of pharmacy, Ministry of Health, Gaza-Palestine), Dr. Aleksandar Radu, Adaptive Sensors Group, National Centre for Sensor Research, School of Chemical Sciences, Dublin City University, Dublin 9, Ireland, Prof. Yousry M. Issa and Prof. Hosny Ibrahim (Cairo University-Egypt) 
Table 3. Results for determination of PDCI in ampoules and urine samples using PD-CMCPE.

\begin{tabular}{|c|c|c|c|c|c|}
\hline Sample & Method* & $\mathrm{PD} / \mathrm{mg}^{\mathrm{a}}$ & Recovery \% & $\operatorname{RSD}^{\mathrm{b}} \%$ & Standard error \\
\hline \multicolumn{6}{|l|}{ Ampoule } \\
\hline & SDM & 0.0248 & 96.8 & 0.85 & 0.025 \\
\hline & & 0.248 & 97.8 & 0.48 & 0.032 \\
\hline & $\mathrm{CCM}$ & 0.0355 & 101.5 & 0.35 & 0.054 \\
\hline & & 0.355 & 100.8 & 0.27 & 0.033 \\
\hline \multicolumn{6}{|l|}{ Urine } \\
\hline & SDM & 0.0248 & 96.6 & 0.74 & 0.021 \\
\hline & & 0.248 & 97.8 & 1.02 & 0.017 \\
\hline & $\mathrm{CCM}$ & 0.0355 & 101.5 & 1.33 & 0.051 \\
\hline & & 0.355 & 100.8 & 1.08 & 0.041 \\
\hline \multicolumn{6}{|c|}{ PTM using Na-TPB and PTA as a titrant } \\
\hline \multirow[t]{2}{*}{ Na-TPB } & & 1.42 & 100.5 & 0.72 & 0.026 \\
\hline & & 14.2 & 100.0 & 0.29 & 0.022 \\
\hline \multirow[t]{2}{*}{ PTA } & & 1.42 & 101.2 & 0.36 & 0.019 \\
\hline & & 14.2 & 103.0 & 0.44 & 0.047 \\
\hline
\end{tabular}

${ }^{\mathrm{a}}$ Milligrams taken of $\mathrm{PDCl}$ in ampoules or spiked to urine samples, ${ }^{\mathrm{b}}$ Average of three determinations, Methods* (used in analytical applications) SDM: standard additions method, CCM: calibration curve method, PTM: potentiometric titration method.

Table 4. Comparison of the proposed pethidine sensor with published sensors.

\begin{tabular}{ccccc}
\hline Reference & $\mathrm{S}$ & $\mathrm{C} . \mathrm{R}$ & $\mathrm{LOD}$ & $\mathrm{R}_{(\mathrm{s})}$ \\
\cline { 2 - 4 }$[10]$ & 55.3 & $1.0 \times 10^{-5}-1.0 \times 10^{-2}$ & $3.3 \times 10^{-6}$ & 10 \\
{$[11]$} & 53.7 & $1.0 \times 10^{-5}-1.0 \times 10^{-2}$ & $9.9 \times 10^{-7}$ & $<30$ \\
{$[12]$} & 51.8 & $1.0 \times 10^{-5}-1.0 \times 10^{-2}$ & $2.2 \times 10^{-6}$ & $<30$ \\
{$[13]$} & 56.7 & $5.0 \times 10^{-6}-1.0 \times 10^{-2}$ & $8.2 \times 10^{-7}$ & $<30$ \\
{$[14]$} & 53.5 & $1.0 \times 10^{-5}-1.0 \times 10^{-3}$ & $4.4 \times 10^{-6}$ & 30 \\
Present work & 54.2 & $2.1 \times 10^{-6}-1.0 \times 10^{-2}$ & $7.3 \times 10^{-7}$ & $5-8$ \\
\hline
\end{tabular}

C.R.: concentration range (M), LOD: limit of detection, $\mathrm{S}$ : slope (mV/decade), $\mathrm{R}_{(\mathrm{s})}$ : response time.

for encouragement, support and providing facilities for research.

\section{References}

[1] S. White and S. H. Y. Wong, "Guidelines for Therapeutic Drug Monitoring Services," In: A. Warner and T. Annesley, Eds., The National Academy of Clinical Biochemistry, Washington, 1999, pp. 63-73.

[2] P. A. Greenwood, C. Merrin, T. McCreedy and G. M. Greenway, "Chemiluminescence $\mu \mathrm{TAS}$ for the Determination of Atropine and Pethidine," Talanta, Vol. 56, No. 3, 2002, pp. 539-545.

[3] B. Han, Y. Du and E. Wang, "Simultaneous Determina- tion of Pethidine and Methadone by Capillary Electrophoresis with Electrochemiluminescence Detection of Tris(2,2'-bipyridyl)ruthenium(II)," Microchemical Journal, Vol. 89, No. 2, 2008, pp. 137-141.

[4] T. G. Venkateshwaran, J. T. Stewart and D. T. King, "HPLC Determination of Morphine-Ondansetron and Meperidine-Ondansetron Mixture in $0.9 \%$ Sodium Chloride Injection," Journal of Liquid Chromatography \& Related Technologies, Vol. 19, No. 8, 1996, pp. 1329-1338.

[5] C. R. Meatherall, D. R. P. Guay and R. P. Dvid, "Analysis of Meperidine and Normeperidine in Serum and Urine by High-Performance Liquid Chromatography," Journal of Liquid Chromatography, Vol. 338, 1985, pp. 141-149. 
[6] S. W. Myung, S. Kim, J. H. Park, M. Kim, J. C. Lee and T. J. Kim, "Solid-Phase Microextraction for the Determination of Pethidine and Methadone in Human Urine Using Gas Chromatography with Nitrogen-Phosphorus Detection," Analyst, Vol. 124, No. 9, 1999, pp. 1283-1286.

[7] F. Liu, X. Y. Hu and Y. Luo, "Investigation of Meperidine and Its Metabolites in Urine of an Addict by Gas Chromatography-Flameionization Detection And Gas Chromatography-Mass Spectrometry," Journal of Chromatography B: Biomedical Sciences and Applications, Vol. 658, 1994, pp. 375-379.

[8] A. Ishii, M. Tanaka, R. Kurihara, K. Watanabe-Suzuki, T. Kumazawa, H. Seno, O. Suzuki and Y. Katsumata, "Sensitive Determination of Pethidine in Body Fluids by Gas Chromatography-Tandem Mass Spectrometry," Journal of Chromatography B, Vol. 792, 2003, pp. 117-121.

[9] H. Farsam and M. R. Nadjari-Moghaddam, "Spectrophotometric Determination of Meperidine Hydrochloride in Pharmaceutical Preparations by Complexation with Bromocresol Green," Journal of Pharmaceutical and Biomedical Analysis, Vol. 2, 1984, pp. 543-547

[10] A. Shalaby, M. El-Tohamy, M. El-Maamly and H. Y. Aboul-Enein, "Potentiometric Membrane Sensor for the Selective Determination of Pethidine in Pharmaceutical Preparations and Biological Fluids," Annali di Chimica, Vol. 97, No. 10, 2007, pp. 1065-1074.

[11] Z. H. Liu, M. L. Wen and J. Xiong, "A Pethidine Selective Polymeric Membrane Electrode Based on PethidineSilicotungstate," Analytical Sciences, Vol. 16, No. 8, 2000, pp. 885-887.

[12] Z. H. Liu, M. L. Wen and J. Xiong, "Plastic Membrane Electrode for the Potentiometric Determination of PethiDine Hydrochloride in Pharmaceutical Preparations," Fresenius Journal of Analytical Chemistry, Vol. 368, No. 4, 2000, pp. 335-337.

[13] Z. H. Liu, M. L. Wen, Y. Yao and J. Xiong, "Plastic Pethidine Hydrochloride Membrane Sensor and Its Pharmaceutical Applications," Sensors and Actuators B, Vol. 72, 2001, pp. 219-223.

[14] Z. H. Liu, M. L. Wen, Y. Yao and J. Xiong, "A Pethidine Selective Polymeric Membrane Electrode," Boletin de la Sociedad Chilena de Quimica, Vol. 47, No. 2, 2002, pp. 163-168.

[15] H. Ibrahim, Y. M. Issa and H. M. Abu-Shawish, "Chemically Modified Carbon Paste Electrode of Dicyclomine Hydrochloride in Batch and in FIA Conditions," Analytical Sciences, Vol. 20, No. 5, 2004, pp. 911-916.

[16] A. O. Santini, H. R. Pezza, J. E. de Oliveira and L. Pezza, "Development of a Potentiometric Flufenamate ISE and its Application to Pharmaceutical and Clinical Analyses," Journal of the Brazilian Chemical Society, Vol. 19, No. 1, 2008. pp. 162-168.

[17] Y. M. Issa, H. Ibrahim and H. M. Abu-Shawish, "Carbon Paste Electrode for the Potentiometric Flow Injection Analysis of Drotaverine Hydrochloride in Serum and Urine," Microchim Acta, Vol. 150, No. 1, 2005, pp. 47-54.

[18] H. M. Abu-Shawish, "Potentiometric Response of Modi- fied Carbon Paste Electrode Based on Mixed Ion-Exchangers," Electroanalysis, Vol. 20, No. 5, 2008, pp. 491-497.

[19] H. Ibrahim, Y. M. Issa and H. M. Abu-Shawish, "Potentiometric Flow Injection Analysis of Mebeverine Hydrochloride in Serum and Urine," Journal of Pharmaceutical and Biomedical Analysis, Vol. 36, No. 5, 2005, pp. 1053-1061.

[20] G. A. E. Mostafa, "Development and Characterization of Ion Selective Electrode for the Assay of Antimony," Talanta, Vol. 71, No. 4, 2007, pp. 1449-1454.

[21] H. Ibrahim, Y. M. Issa and H. M. Abu-Shawish, "Potentiometric Flow Injection Analysis of Dicyclomine Hydrochloride in Serum, Urine and Milk," Analytica Chimica Acta, Vol. 532, No. 1, 2005, pp. 79-88.

[22] V. S. Bhat, V. S. Ijeri and K. A. Srivastava, "Coated Wire Lead(II) Selective Potentiometric Sensor Based on 4-tertbutylcalix[6]arene," Sensors and Actuators B, Vol. 99, No. 1, 2004, pp. 98-105.

[23] H. M. Abu-Shawish, S. M. Saadeh, K. Hartani and H. M. Dalloul, "A Comparative Study of Chromium(III) IonSelective Electrodes Based on N,N-Bis(salicylidene)-ophenylenediaminatechromium(III)," Journal of the Iranian Chemical Society, Vol. 6, No. 4, 2009, pp. 729-737.

[24] M. Arvand and S. A. Asadollahzadeh, "Ion-Selective Electrode for Aluminum Determination in Pharmaceutical Substances, Tea Leaves and Water Samples," Talanta, Vol. 75, No. 4, 2008, pp. 1046-1054.

[25] M. Shamsipur, M. Yousefi, M. Hosseini and M. R. Ganjali, "Lanthanum(III) PVC Membrane Electrodes Based on 1,3,5-trithiacyclohexane," Analytical Chemistry, Vol. 74, No. 21, 2002, pp. 5538-5543.

[26] E. A. Cummings, P. Mailley, S. Linquette-Mailley, B. R. Eggins, E. T. McAdams and S. McFadden, "Amperometric Carbon Paste Biosensor Based on Plant Tissue for the Determination of Total Flavanol Content in Beers," Analyst, Vol. 123, No. 10, 1998, pp. 1975-1980.

[27] J. S'anchez and M. Valle, "Determination of Anionic Surfactants Employing Potentiometric Sensors-A review," Critical Reviews in Analytical Chemistry, Vol. 35, No. 1, 2005, pp. 15-29.

[28] X. B. Zhang, Z. X. Han, Z. H. Fang, G. L. Shen and R. Q. $\mathrm{Yu}$, "5,10,15-Tris(pentafluorophenyl)corrole as Highly Selective Neutral Carrier for a Silver Ion-Sensitive Electrode," Analytica Chimica Acta, Vol. 562, No. 2, 2006 , pp. 210-215.

[29] P. R. Buck and E. Lindner, "IUPAC Recommendation for Nomenclature of Ion-Selective Electrodes," Pure and Applied Chemistry, Vol. 66, No. 12, 1994, pp. $2527-$ 2536.

[30] H. M. Abu-Shawish, S. M. Saadeh and A. R. Hussien, "Enhanced Sensitivity for $\mathrm{Cu}(\mathrm{II})$ by a Salicylidine-Functionalized Polysiloxane Carbon Paste Electrode," Talanta, Vol. 76, No. 3, 2008, pp. 941-948.

[31] H. M. Abu-Shawish, "A Mercury(II) Selective Sensor based on N,N'-bis(salicylaldehyde)-phenylenediamine as Neutral Carrier for Potentiometric Analysis in Water 
Samples," Journal of Hazardous Materials, Vol. 167, No. 1-3, 2009, pp. 602-608.

[32] Y. Umezawa, P. Buhlmann, K. Umezawa, K. Tohda and S. Amemiya, "Potentiometric Selectivity Coefficients of Ion-Selective Electrodes," Pure and Applied Chemistry, Vol. 72, No. 10, 2000, pp. 1851-2082.

[33] S. Chandra, H. Agarwal and C.K. Singh, "A highly Selective and Sensitive Thorium(IV) PVC Membrane Electrode Based on a Dithio-Tetraaza Macrocyclic Compound," Analytical Sciences, Vol. 23, No. 4, 2007, pp.
469-473.

[34] H. X. Wang and M. Pu, "A Method of Determining Selectivity Coefficients Based on the Practical Slope of Ion Selective Electrodes," Chinese Chemical Letters, Vol. 13, No. 4, 2002, pp. 355-358.

[35] M. Arvand, M. Vejdani and M. Moghimi, "Construction and Performance Characterization of an Ion Selective Electrode for Potentiometric Determination of Atenolol in Pharmaceutical Preparations," Desalination, Vol. 225, No. 1-3, 2008, pp. 176-184. 